\title{
Genetic screening of patients with medullary thyroid cancer in a referral center in Greece during the past two decades
}

\author{
H-L Sarika, A Papathoma', M Garofalaki², K Saltiki, T Pappa, \\ K Pazaitou-Panayiotou ${ }^{3}$, E Anastasiou ${ }^{4}$ and M Alevizaki
}

Endocrine Unit, Department of Clinical Therapeutics, School of Medicine, Alexandra General Hospital, Athens University, Athens, Greece, ${ }^{1}$ Immunology Department, Alexandra General Hospital, Athens, Greece,

${ }^{2}$ Hematology-Lymphomas Department and BMT Unit, Evaggelismos General Hospital, Athens, Greece,

${ }^{3}$ Department of Endocrinology-Endocrine Oncology, Theageneio Cancer Hospital, Thessaloniki,

Greece and ${ }^{4} 1$ st Endocrine Section and Diabetes Center, Alexandra General Hospital, Athens, Greece
Correspondence

should be addressed

to H-L Sarika

Email

ledasarika@gmail.com

\begin{abstract}
Objective: Mutations in the RET gene are responsible for hereditary medullary thyroid cancer (MTC) and may vary between ethnic groups. We report the spectrum of mutations detected in patients with MTC in a referral center in Greece.

Patients and methods: Screening for RET mutations was performed in 313 subjects from 188 unrelated families: 51 patients had clinical suspicion for familial disease, 133 were apparently sporadic, four patients had only $C$ cell hyperplasia, and 125 were family members. Exons $8,10,11$, and 13-16 were screened.

Results: A total of 58 individuals (30.85\%) were RET mutations carriers, $120(63.8 \%)$ were finally classified as sporadic, 13 apparently sporadic cases $(9.8 \%)$ were identified with RET mutation: ten carried the exon 8 at codon 533 mutation (previously reported), two the exon 14 at codon 804 mutation, and one the exon 13 at codon 768 mutation. Six patients (3.19\%) with clinical features of multiple endocrine neoplasia type $2 \mathrm{~A}$ and negative for RET mutations were classified as 'unknown cause'. The mutations of hereditary cases were as follows: 21 cases (36.2\%) in exon 8 codon 533,19 (32.8\%) in exon 11 codon 634 , nine $(15.5 \%)$ in exon 10 , five $(8.6 \%)$ in exon 16 , three $(5.2 \%)$ in exon 14 codon 804 , and one in exon 13 codon $768(1.7 \%)$. Conclusion: The spectrum of RET mutations in Greece differs from that in other populations and the prevalence of familial cases is higher. The exon 8 (Gly533Cys) mutation was the most prevalent in familial cases unlike other series, followed by exon 11 (codon 634) mutations which are the most frequent elsewhere. The wide application of genetic screening in MTC reveals new molecular defects and helps to characterize the spectrum of mutations in each ethnic group.
\end{abstract}

\section{Introduction}

Medullary thyroid carcinoma (MTC) constitutes 5-10\% of all thyroid malignancies. About $25 \%$ of the cases of MTC are familial and the disease is inherited in an autosomal dominant manner. The inherited forms present as multiple endocrine neoplasia (MEN) syndromes MEN2A and MEN2B, which are characterized by occasional coexistence with pheochromocytoma (PHEO) and - in the case of MEN2A - with primary hyperparathyroidism (PHP). Those without further tumors are characterized as familial MTC (FMTC) only (1).
(C) 2015 European Society of Endocrinology Printed in Great Britain
The molecular pathology of inherited MTC is constitutive activation of the RET proto-oncogene. The human RET gene comprises 21 exons and its size is $53.3 \mathrm{~kb}$. It encodes a tyrosine kinase receptor with a cysteine-rich extracellular domain, a transmembrane domain, and an intracellular tyrosine kinase domain $(1,2)$.

The RET gene plays an important role in cell signaling in neural tissue, especially during the early stages of development. Mutations in the gene lead to abnormalities in cell proliferation and differentiation of tissues derived

Published by Bioscientifica Ltd 
from neural crest cells, such as the C-cells of the thyroid and the adrenal medulla (3). The number and type of recognized RET mutations have increased over the last years due to the wider application of genetic screening. Mutations affecting the extracellular domain of the protein in codons 609, 611, 618, 620, 630, and 634 activate the tyrosine kinase receptor by ligand-independent dimerization and cross phosphorylation. Mutations affecting the intracellular domain involve codons 768, 790, 791 (exon 13), 804 (exon 14), 883 and 891 (exon 15), and 918 (exon 16) and these may interfere with intracellular ATP binding of the tyrosine kinase receptor (4).

Carriers of mutations in codon 634 present frequently the full-blown MEN2 syndrome where MTC may be accompanied by PHEO in 50\% and PHP in $25 \%$ of the cases. Mutations in exon 10 at codons $609,611,618$, and 620 and in exon 11 at codon 634 (5) are the commonest among the familial cases accounting for $88-98 \%$ of the cases. Less frequently, mutations have been reported in the non-cysteine $R E T$ region such as at codon 804 in exon 14, codon 883 in exon 15, and codon 533 in exon $8(6,7)$. Mutations at codon 918 in exon 16 are found in $95 \%$ of MEN2B patients and appear to be specific for this syndrome (5). MEN2 is a rare disease. In recent years, referral centers in several countries have gathered a considerable number of families and published their results which enabled us to correlate RET mutations with the phenotype $(8,9)$.

Currently screening of the RET gene is widely applied for the detection of inherited disease, the identification of gene carriers, and thus for preclinical diagnosis of MTC in these families.

As the spectrum of mutations may vary between centers, it is important to characterize the mutations in each population. This information could differentiate the orientation of the genetic analysis to include more than the standard RET mutation screening panel which includes only the exons 10,11,13-16. In this study, we report the results of RET gene screening performed in the Endocrine Units of 'ALEXANDRA' University Hospital, over the last 20 years in subjects diagnosed with MTC after histological confirmation and in family members of $R E T$-positive patients with MTC.

\section{Subjects and methods}

\section{Subjects}

Over a period of 20 years we examined 313 Greek individuals for mutations of the RET gene in exons 8,10 ,
11, and 13-16 either because they had been diagnosed with MTC, or because they had a relative with MTC. In our center, the majority of newly diagnosed cases from central and southern Greece are referred.

One hundred and eighty-eight of them (120 women and $68 \mathrm{men}$ ) were independent individuals belonging to different families. Of these, 133 presented as sporadic MTC cases without other features of MEN2 or family history, 51 patients had clinical suspicion for MEN2 and four patients had only $\mathrm{C}$ cell hyperplasia (CCH). Of the 51 suspects for MEN2, 22 had characteristic features of MEN2A syndrome (MTC with PHEO or PHP), five presented with clinical features of MEN2B syndrome, 23 had familial disease, with at least one relative with proven MTC or suspicious for MTC (such as a grandparent having died of 'neck tumor'). One patient who only had bilateral PHEO without MTC was included in the analysis because he was found to carry the exon 11, codon 634 mutation which is the characteristic of MEN2 syndrome. This patient has not developed MTC yet. His latest basal calcitonin (CT) levels were $12 \mathrm{pg} / \mathrm{ml}$ and after calcium infusion $128 \mathrm{pg} / \mathrm{ml}$ (last screening was at the age of 32 years); thyroid ultrasound was normal. Four patients had only $\mathrm{CCH}$. This group was identified from histological findings after thyroidectomy was performed for multinodular goiter. The remaining 125 individuals were family members of RET carriers. Informed consent was given by all subjects participating in the study for RET screening. The investigation was approved by the hospital ethics committee.

\section{Methods}

DNA extraction, PCR amplification, and sequencing $>$ A venous blood sample was collected from all patients in EDTA-coated tubes. Genomic DNA was purified from peripheral blood lymphocytes using the QIAMP DNA Mini Kit (Qiagen). RET exons 8, 10, 11, and 13-16 were analyzed using PCR and DNA sequencing as follows:

During the first 10 years, we used the manual Sanger sequencing method (Cycle Sequencing Kit, Amersham). More recently, the Mega Bace Sequencing Analyzer was used. The sequencing reaction was performed in a $20 \mu \mathrm{l}$ final volume containing $5 \mathrm{pmol}$ of the relevant sequencing primers of DYEnamic ET dye terminator kit of Mega Bace, Amersham Biosciences. In $45 \%$ of the samples, the results were confirmed with pyrosequencing (Pyrosequencing $A B$, Uppsala, Sweden).

Specifically, the screening for exon 8 mutation was performed in all our samples by allelic discrimination using Custom TaqMan SNP Genotyping assay in a 7500 
Real-time PCR System (Applied Biosystems). In the ten positive samples and most of the negative for apparently sporadic patients, sequencing was also performed to confirm the results (7).

\section{Results}

Genetic screenings of the 188 unrelated patients revealed 13 different RET mutations in 58 carriers (Table 1). Of them, 29.3\% (17/58) had MEN2A syndrome, 8.6\% (5/58) MEN2B syndrome, and 62.1\% (36/58) had FMTC (Fig. 1).

Six subjects with MTC who had additional characteristics of MEN2 syndrome (one patient had MTC+ $\mathrm{PHEO}+$ neurofibromas, two had MTC + PHEO, and three patients had MTC + PHP), all with negative family history, were found RET negative and classified as of 'unknown cause'. The four patients with $\mathrm{CCH}$ were RET negative.

Of the 133 patients considered as sporadic, 13 were found RET positive (9.8\%): ten of them carried the exon 8 codon 533 mutation as previously reported (7), two were found to carry the exon 14, codon 804 mutation and one had the exon 13 , codon 768 mutation. The remaining 120 patients with only MTC and no RET mutation were classified as sporadic.

In all cases, MTC was the first manifestation of the syndrome except for a 29-year-old man who presented to our center with bilateral PHEO as the only manifestation. Genetic screening revealed a mutation at codon 634 in exon 11 and the patient was assigned to the MEN2A group. None of his brothers or sisters was found to carry the mutation; the parents were not available to be tested. This patient had not developed MTC at his latest screening.

We had the opportunity to examine one large kindred with 27 members (family number 1) through four generations (Fig. 2). The index case was a 32-year-old woman originally characterized as FMTC (Fig. 2, C10). Twenty-one out 27 family members screened in our center were found to carry the $620 \mathrm{TGC} / \mathrm{TAC}$ mutation in exon 10. After 8 years of follow-up, one MTC woman in the third generation developed PHEO (Fig. 2, C4); recently, her daughter also developed PHEO (Fig. 2, D3). Interestingly, a young girl in the fourth generation of another branch of the same family developed Hirschsprung's disease (HIRSC; Fig. 2, D1). Thus, during follow-up, this family was reclassified as MEN2A (Table 1).

\section{Distribution of RET mutations}

In the group of 58 RET positive patients, the most prevalent mutation was the Gly533Cys of exon 8
(36.2\%, 21/58) followed by mutations at codon 634 at a percentage of $32.8 \%$ (19/58). The Cys634Arg substitution was present in $57.9 \%$ of codon 634 mutations (11/19), while its prevalence in RET positive cases was 19\% (11/58). A lower prevalence of mutations was found at exon 10 (15.5\%, 9/58); exon 16, codon 918 (8.6\%, 5/58); exon 14, codon 804 (5.2\%, 3/58); and exon 13, codon 768 $(1.7 \%, 1 / 58)$ (Fig. 3). We did not find mutations in codons 609 and 611 of exon 10 or in codons 790/791 of exon 13 in our patients (Fig. 3).

\section{Family members}

We examined 125 family members belonging to the 58 $R E T$-positive families: 61 of them $(48.8 \%)$ were found to carry a RET mutation and 64 were negative (Table 1 ).

\section{Discussion}

The RET mutation testing for inherited MTC is a unique paradigm of the value of genetic screening in the early diagnosis, prevention, and treatment of cancer, which has been of great importance for the management of patients with MTC. The indications for screening and intervention follow a mutation-based risk classification for MTC patients and carriers according to the guidelines of the American Thyroid Association (ATA) (10) and the European Thyroid Association (ETA) (11). However, the spectrum of mutations is not the same in all ethnic groups. The first International Consortium for RET mutation analysis identified only eight hot spots for mutations and described their distribution in the subtypes of MEN2 syndromes (MEN2A, MEN2B, and FMTC) (4). However, in the two largest series that have been presented recently, several new mutations have been described and a large variability in the mutation distribution in the MEN2 population in different countries in Europe and worldwide has been shown. Forty different mutations are mentioned in both reports: one report from three European countries; Germany, Italy, and France (8) and the other from Italy (9).

\section{Variability of mutations spectrum in different ethnic groups}

The exon 8 Gly533Cys mutation appears to be the characteristic of our ethnic group with a prevalence of $36.2 \%$ in hereditary cases. This mutation appears to be specific to the Mediterranean region $(7,12)$ and has rarely been found in other series. Interestingly, the first 
Table 1 Clinical characteristics of the index cases in each of the families diagnosed with hereditary MTC in our center. The affected codon, the resulting amino/acid change, and relative exon are also given.

\begin{tabular}{|c|c|c|c|c|c|c|c|}
\hline $\begin{array}{l}\text { Family } \\
\text { no. }\end{array}$ & Age & Exon & Codon & Base change & $\begin{array}{l}\text { Amino/acid } \\
\text { change }\end{array}$ & Clinical diagnosis & $\begin{array}{l}\text { GC/total family } \\
\text { members }\end{array}$ \\
\hline 1 & 32 & 10 & 620 & TGC/TAC & CYS/TYR & MEN2A (MTC + PHEO + HIRSC) & $21 / 27$ \\
\hline 2 & 36 & 10 & 618 & TGC/CGC & CYS/ARG & MEN2A (MTC + PHEO) & $1 / 7$ \\
\hline 3 & 35 & 10 & 620 & TGC/CGC & CYS/ARG & FMTC & $2 / 5$ \\
\hline 4 & 30 & 10 & 620 & TGC/CGC & CYS/ARG & FMTC & $3 / 3$ \\
\hline 5 & 31 & 10 & 618 & TGC/TAC & CYS/TYR & FMTC & $1 / 4$ \\
\hline 6 & 50 & 10 & 620 & TGC/CGC & CYS/ARG & FMTC & $2 / 3$ \\
\hline 7 & 20 & 10 & 618 & TGC/TCC & CYS/SER & FMTC & $1 / 1$ \\
\hline 8 & 60 & 10 & 618 & TGC/CGC & CYS/ARG & MEN2A (MTC + PHEO) & $1 / 1$ \\
\hline 9 & 35 & 10 & 620 & TGC/TTC & CYS/PHE & FMTC & $1 / 1$ \\
\hline 10 & 29 & 11 & 634 & TGC/CGC & CYS/ARG & MEN2A (MTC+PHEO) & $3 / 6$ \\
\hline 11 & 41 & 11 & 634 & TGC/TAC & CYS/TYR & FMTC & $2 / 3$ \\
\hline 12 & 34 & 11 & 634 & TGC/CGC & CYS/ARG & MEN2A (MTC + PHEO + PHP) & $4 / 8$ \\
\hline 13 & 50 & 11 & 634 & TGC/CGC & CYS/ARG & MEN2A (MTC + PHEO) & $6 / 8$ \\
\hline 14 & 28 & 11 & 634 & TGC/CGC & CYS/ARG & FMTC & $3 / 6$ \\
\hline 15 & 20 & 11 & 634 & TGC/TAC & CYS/TYR & MEN2A (MTC + PHEO) & $2 / 3$ \\
\hline 16 & 31 & 11 & 634 & TGC/CGC & CYS/ARG & FMTC & $1 / 3$ \\
\hline 17 & 25 & 11 & 634 & TGC/TAC & CYS/TYR & FMTC & $2 / 3$ \\
\hline 18 & 30 & 11 & 634 & TGC/TAC & CYS/TYR & FMTC & $1 / 1$ \\
\hline 19 & 25 & 11 & 634 & TGC/TTC & CYS/PHE & MEN2A (MTC + PHP) & $4 / 7$ \\
\hline 20 & 42 & 11 & 634 & TGC/TAC & CYS/TYR & MEN2A (MTC+ PHEO) & $4 / 7$ \\
\hline 21 & 35 & 11 & 634 & TGC/TAC & CYS/TYR & MEN2A (MTC + PHEO) & $1 / 7$ \\
\hline 22 & 25 & 11 & 634 & TGC/CGC & CYS/ARG & MEN2A (PHEO BILAT) & $1 / 1$ \\
\hline 23 & 33 & 11 & 634 & TGC/CGC & CYS/ARG & MEN2A (MTC+PHEO) & $2 / 3$ \\
\hline 24 & 29 & 11 & 634 & TGC/TAC & CYS/TYR & FMTC & $1 / 1$ \\
\hline 25 & 23 & 11 & 634 & TGC/CGC & CYS/ARG & MEN2A (MTC+PHEO+PHP) & $1 / 2$ \\
\hline 26 & 21 & 11 & 634 & TGC/CGC & CYS/ARG & MEN2A (MTC+PHEO) & $2 / 3$ \\
\hline 27 & 22 & 11 & 634 & TGC/CGC & CYS/ARG & FMTC & $2 / 2$ \\
\hline 28 & 36 & 11 & 634 & TGC/CGC & CYS/ARG & FMTC & $1 / 1$ \\
\hline 29 & 36 & 8 & 533 & GGC/TGC & GLY/CYS & FMTC & $1 / 1$ \\
\hline 30 & 40 & 8 & 533 & GGC/TGC & GLY/CYS & FMTC & $1 / 1$ \\
\hline 31 & 50 & 8 & 533 & GGC/TGC & GLY/CYS & FMTC & $2 / 3$ \\
\hline 32 & 51 & 8 & 533 & GGC/TGC & GLY/CYS & FMTC & $2 / 3$ \\
\hline 33 & 28 & 8 & 533 & GGC/TGC & GLY/CYS & FMTC & $1 / 1$ \\
\hline 34 & 62 & 8 & 533 & GGC/TGC & GLY/CYS & FMTC+PTC & $1 / 1$ \\
\hline 35 & 38 & 8 & 533 & GGC/TGC & GLY/CYS & FMTC & $3 / 3$ \\
\hline 36 & 39 & 8 & 533 & GGC/TGC & GLY/CYS & FMTC & $1 / 1$ \\
\hline 37 & 55 & 8 & 533 & GGC/TGC & GLY/CYS & FMTC & $4 / 4$ \\
\hline 38 & 50 & 8 & 533 & GGC/TGC & GLY/CYS & MEN2A (MTC+PHEO BILAT) & $1 / 1$ \\
\hline 39 & 68 & 8 & 533 & GGC/TGC & GLY/CYS & FMTC & $1 / 1$ \\
\hline 40 & 72 & 8 & 533 & GGC/TGC & GLY/CYS & FMTC & $1 / 3$ \\
\hline 41 & 43 & 8 & 533 & GGC/TGC & GLY/CYS & FMTC & $1 / 1$ \\
\hline 42 & 36 & 8 & 533 & GGC/TGC & GLY/CYS & FMTC & $1 / 1$ \\
\hline 43 & 58 & 8 & 533 & GGC/TGC & GLY/CYS & MEN2A (MTC+PHEO) & $1 / 2$ \\
\hline 44 & 40 & 8 & 533 & GGC/TGC & GLY/CYS & FMTC & $2 / 2$ \\
\hline 45 & 56 & 8 & 533 & GGC/TGC & GLY/CYS & MEN2A (MTC+PHP) & $1 / 1$ \\
\hline 46 & 18 & 8 & 533 & GGC/TGC & GLY/CYS & FMTC & $4 / 6$ \\
\hline 47 & 46 & 8 & 533 & GGC/TGC & GLY/CYS & FMTC & $1 / 1$ \\
\hline 48 & 47 & 8 & 533 & GGC/TGC & GLY/CYS & FMTC & $1 / 2$ \\
\hline 49 & 37 & 8 & 533 & GGC/TGC & GLY/CYS & FMTC & $3 / 5$ \\
\hline 50 & 15 & 16 & 918 & ATG/ACG & MET/THR & MEN2B & $1 / 4$ \\
\hline 51 & 15 & 16 & 918 & ATG/ACG & MET/THR & MEN2B & $1 / 1$ \\
\hline 52 & 15 & 16 & 918 & ATG/ACG & MET/THR & MEN2B & $1 / 1$ \\
\hline 53 & 16 & 16 & 918 & ATG/ACG & MET/THR & MEN2B & $1 / 1$ \\
\hline 54 & 6 & 16 & 918 & ATG/ACG & MET/THR & MEN2B & $1 / 1$ \\
\hline 55 & 28 & 13 & 768 & GAG/GAC & GLU/ASP & FMTC & $1 / 1$ \\
\hline 56 & 50 & 14 & 804 & GTG/ATG & LEU/MET & FMTC & $1 / 1$ \\
\hline 57 & 43 & 14 & 804 & GTG/ATG & LEU/MET & FMTC & $1 / 1$ \\
\hline 58 & 48 & 14 & 804 & GTG/ATG & LEU/MET & FMTC & $1 / 1$ \\
\hline
\end{tabular}

MTC, medullary thyroid cancer; GC, gene carriers; FMTC, familial MTC; MEN2B, multiple endocrine neoplasia type 2B; PHP, primary hyperparathyroidism; PHEO, pheochromocytoma; HIRSC, Hirschsprung's disease; PTC, papillary thyroid cancer. 
Gly533Cys-positive family recently reported in USA was of Greek ancestral origin (13). This rare mutation has occasionally been identified in other Mediterranean regions; at least one Gly533Cys family has been reported in South Portugal and a few families in the French registry (V Leite and D Prunier 2014, personal communication). One patient of Slovenian origin with the same mutation has also been reported in Ireland (14). The fact that not every RET gene screening program includes exon 8 might be the reason for the rarity of Gly533Cys-positive families outside Western Europe.

Two other countries are reported to have a high prevalence of unusual mutations: a large multicenter study form Italy (ItaMEN study) (9) reported that the rare mutation Val804Met in exon 14 is found with a prevalence of $19.6 \%$, especially in Sardinia 59\%, followed by the Cys634Arg substitution in exon $11(13.6 \%)(9,15)$. At codons 790/791 in exon 13, another mutations' spot appears with high prevalence in Germany at 13 and 7\% respectively (8).

Apparently, founder effects are responsible for this variability in the frequency of mutations. Notably, the codon 533 in exon 8 mutation is found especially in the southern part of central Greece and the south east region of Peloponnese (7). So far, no exon 8 mutations have been reported at a referral center of Northern Greece (K Pazaitou-Panayiotou 2014, personal communication). Studies underway indicate that the Greek families may share a common haplotype with the first described family carrying this mutation that was of Brazilian/Spanish origin (R M Maciel and M Alevizaki 2014, unpublished).

The exon 11 mutations that are the most frequent in the literature $(4,8,9)$ come in second range in our center with a percentage of $32.8 \%(19 / 58)$. Eleven of these cases carry the Cys634Arg (TGC/CGC) mutation, which is also the commonest in other series.

In recent years several other groups have published the genetic findings in small series of MTC patients with familial disease. Mutations in both exons 10 or 11 (Spain, Portugal, India, Saudi Arabia, Korea, and Czech Republic) and only 11 (Turkey and Taiwan) have been reported (16, $17,18,19,20,21,22,23)$. Especially in the Czech Republic a higher than usual prevalence of mutations in exons 13 and 14 (17.45 and $13.0 \%$ respectively) has been reported (20).

The compiled data from three European countries that have recently been published show the distribution of different RET mutations as follows: $34.2 \%$ at codon $634,17.2 \%$ at codon $804,10.4 \%$ at codon $918,7.6 \%$ at codon $790,7.2 \%$ at codon $891,7.0 \%$ at codon $620,6.4 \%$ at codon $618,3.2 \%$ at codon $791,2.6 \%$ at codon 768 ,
1.6\% each at codons 609 and 611, and 1.0\% at codon 630 . In this large series, there is no report of mutation at codon 533 in exon 8 (8).

One MTC family with mutation in exon 8 but at the 515 codon (not 533) was reported in Italy by Fazioli et al. (24). A comparison of our data with those of other European cohorts is given in Table 2. Mutations in codons 609,611 , and 790/791, occasionally found in Europe, were not identified in our center. From this table, it is obvious that, with a few exceptions, the highest prevalence still concerns codon 634 in exon 11, which is associated with a more dramatic clinical picture, more frequent $\mathrm{PHEO}$ co-existence, and more aggressive MTC and is thus more frequently identified to represent familial disease.

\section{Phenotype of hereditary cases in our center: the majority are FMTC}

In our center, we have observed one of the highest percentages of hereditary forms of MTC $(30.8 \%, 58 / 188)$ compared with $25 \%$ that are globally reported (11). One cannot exclude a bias, as this was the first center performing RET screening in our country. In a study in the Iranian population, the depicted 13 RET-positive families represent $24.5 \%(13 / 53)$ while in a study from

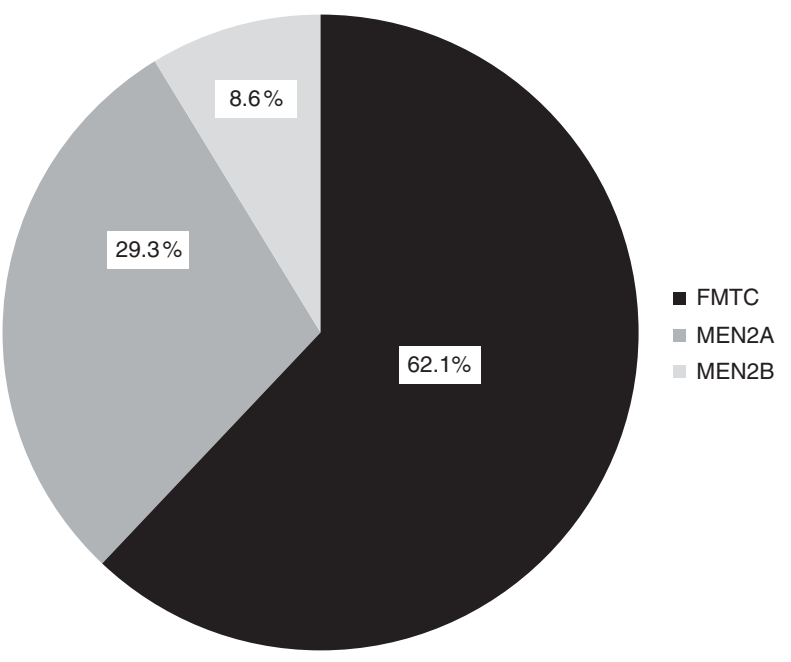

\section{Figure 1}

Distribution of the hereditary (RET positive) cases of medullary thyroid cancer (MTC) after the genetic screening of apparently sporadic cases. One FMTC family has been re-classified as MEN2A after the appearance of pheochromocytoma in the third generation. FMTC, familial MTC; MEN2A, multiple endocrine neoplasia syndrome type $2 \mathrm{~A}$. 


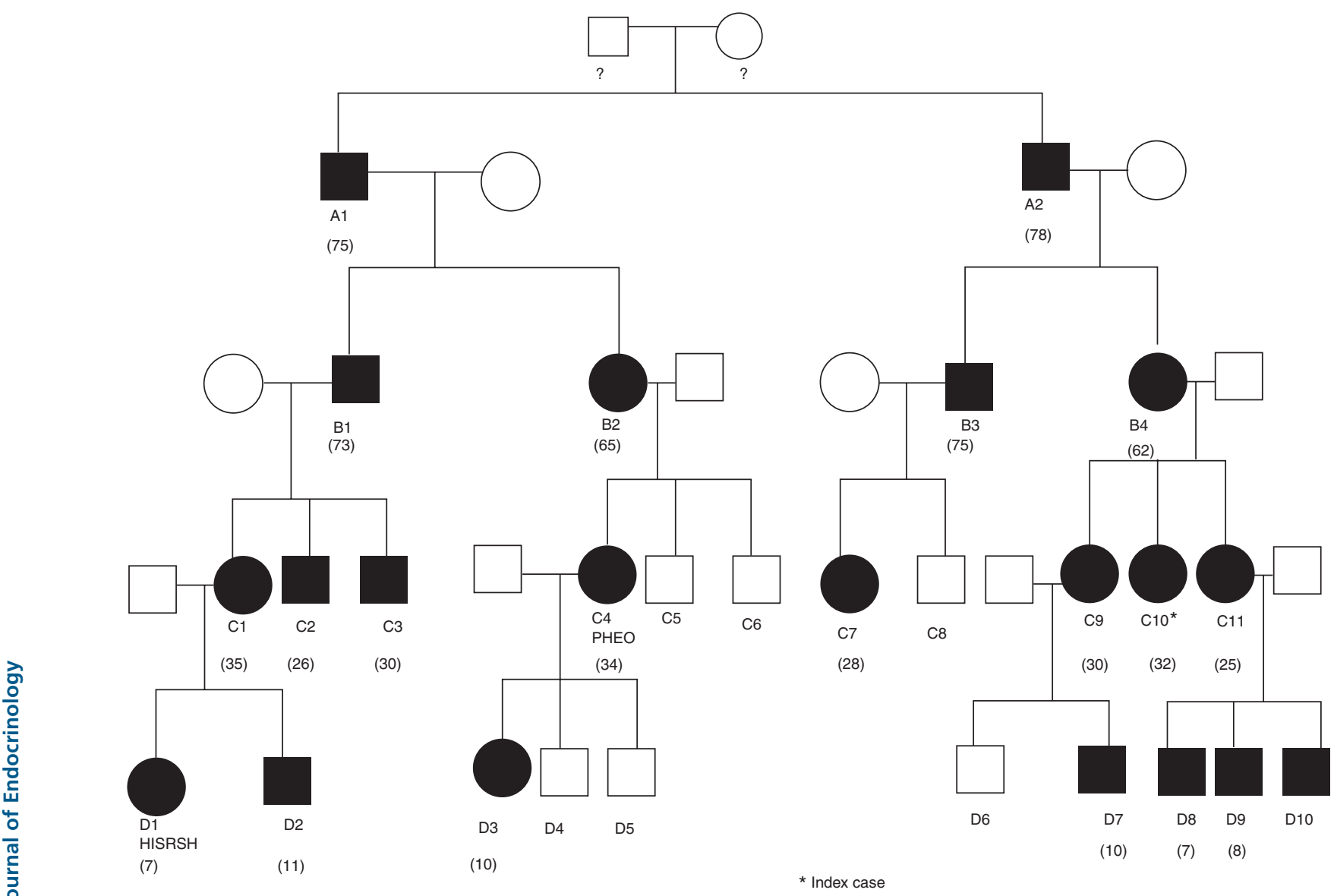

Figure 2

One large kindred followed in our center for four generations. The index case is shown with an asterisk. The age at which the MTC diagnosis was made in each of the RET positive cases is

the Czech Republic they represent $21.7 \%$ (23/106) of MTC patients $(20,25)$. The relevant percentage in Spain is $22.8 \%(26 / 114)(22)$.

The presence of only $\mathrm{CCH}$ was not found to be associated with genetic disease in our series, in agreement with the report by Scheuba et al. (26). Thus, incidental $\mathrm{CCH}$ is probably not a strong indication for genetic screening.

In our center, the prevalence of inherited MTC without any features of MEN2A was higher (62.1\%) compared with the 10-20\% mentioned in the first Consortium for MEN2 (4) or the 35-60\% reported recently by Raue \& Frank-Raue (27). Our findings are closer to the $57.6 \%$ reported in the ItaMEN study (9). It should be noted that in the 'FMTC' group, we have included the cases where pathogenic RET mutation was found even when the shown in parenthesis. PHEO, pheochromocytoma; HIRSC, Hirschsprung's disease. family history was negative, because on many occasions the relatives were not available for the study.

Many investigators consider FMTC as a subtype of MEN2A, given the fact that in some MTC families PHEO or other MEN2A manifestations may appear in the third or fourth generation or later, as in family number 1 in our series. Moers et al. (28) have also reported a large MEN2A family followed through several generations, in which only two subjects developed PHEO in the fourth generation and two developed PHP among the 150 screened family members.

In family number 1 of our series, HIRSC developed for the first time in the fourth generation (Fig. 1, D1). HIRSC in the context of MEN2A syndrome has invariably been associated with exon 10 mutations, which is in agreement with our results (27). Interestingly, $7.5 \%$ of exon 10 


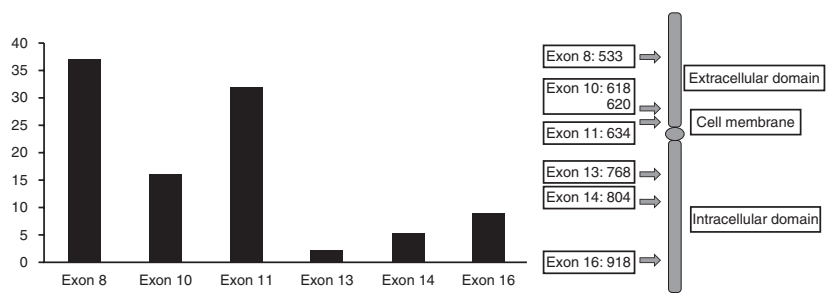

Figure 3

The prevalence (\%) of different RET mutations in our cohort of 58 Greek families with hereditary medullary thyroid cancer (left). The position of mutations (codon and exon) in the RET gene in our cohort is shown in a schematic representation on the right side of the picture.

mutations carriers are reported to have HIRSC (27). For this reason, Fugazzola et al. (29) recommend screening of exon 10 in all individuals with HIRSC. We have considered the possibility that an anticipation phenomenon might have occurred in family number 1 . The mean age at diagnosis in the second generation was 68.7 years dropping to 30 years in the third generation and 8.8 years in the fourth generation. However, TNM stage did not substantially change between second and third generations. It should be taken into account that once the mutation was characterized in a family member, the next generation was tested and operated at a much earlier age.

As concerns the clinical presentation, in our series there is a preponderance of rather mild disease. This is due to the following reasons: the high percentage of FMTC in which MTC appears usually at later age and is less aggressive and also to the high prevalence of the Gly533Cys mutation which is associated with a milder form of the disease.

\section{Conclusions}

Genetic screening is a very useful diagnostic tool and is recommended by ATA (10) for all MTC patients. The ETA guidelines also recommend genetic screening in all apparently sporadic cases (11). This strategy is expected to increase the probability of identifying new MEN2 kindreds. Thus, the mutations associated with lower penetrance are likely to be enriched in other series as well in the future. The reason why the 634 mutation appears to be the most prevalent in practically all the previous publications is obviously the fact that the earlier onset of disease and the frequent combination with PHEO made the referral and diagnosis easier. The identification of the rare occurrence of PHEO in members of families, which for generations were classified as FMTC, stresses the need for continuous awareness for PHEO in such families as well. The recognition of the specific pattern of RET mutations for each country will help toward a more focused screening which is expected both to speed up the diagnosis and also to lower the cost. This is more helpful in areas where there is a high prevalence of rare $R E T$ mutations, not included in the commonly screened panel (exons 10, 11, 13-16) which is likely to be replaced in the future with whole-gene screening when next generation sequencing becomes more widely used.

Table 2 The spectrum of RET mutations identified in families with hereditary medullary thyroid cancer in our center in Greece compared with those described by other European groups. The prevalence $(n(\%))$ of each mutation is shown (data from references $(8,20,22))$.

\begin{tabular}{|c|c|c|c|c|c|c|}
\hline Codon & Germany & Italy & France & Spain & Czech Republic & Greece \\
\hline 533 & 0 & 0 & 0 & $0(0)$ & 0 & $21(36.2)$ \\
\hline 600 & 0 & 0 & 0 & $1(3.85)$ & 0 & 0 \\
\hline 609 & $1(0.5)$ & $6(3)$ & $1(1)$ & $1(3.85)$ & $1(4.2)$ & 0 \\
\hline 611 & $6(2.9)$ & $1(0.5)$ & $1(1)$ & 0 & $1(4.2)$ & 0 \\
\hline 618 & $11(5.4)$ & $15(7.6)$ & $6(6.2)$ & $1(3.85)$ & 0 & $4(6.9)$ \\
\hline 620 & $14(6.8)$ & $9(4.5)$ & $12(12.4)$ & $1(3.85)$ & 0 & $5(8.6)$ \\
\hline 630 & $1(0.5)$ & $4(2)$ & 0 & 0 & 0 & 0 \\
\hline 634 & $73(35.6)$ & $52(26.3)$ & $46(47.4)$ & $17(65.4)$ & $11(45.8)$ & $19(32.8)$ \\
\hline 768 & $2(1)$ & $9(4.5)$ & $2(2.1)$ & $1(3.85)$ & $1(4.2)$ & 1 (1.7) \\
\hline 790 & $26(12.7)$ & $8(4)$ & $4(4.1)$ & 0 & 0 & 0 \\
\hline 791 & $14(6.8)$ & $2(1)$ & 0 & 0 & $3(12.5)$ & 0 \\
\hline 804 & $19(9.3)$ & $52(26.3)$ & $15(15.5)$ & 0 & $3(12.5)$ & $3(5.2)$ \\
\hline 883 & $\begin{array}{c}0 \\
0\end{array}$ & $\begin{array}{c}22(20.01 \\
0\end{array}$ & 0 & 0 & 0 & 0 \\
\hline 891 & $6(2.9)$ & $23(11.6)$ & $7(7.2)$ & $1(3.85)$ & 0 & 0 \\
\hline 918 & $32(15.6)$ & $17(8.7)$ & $3(3.1)$ & $3(11.5)$ & $4(16.6)$ & $5(8.6)$ \\
\hline Total & 205 & 198 & 97 & 26 & 24 & 58 \\
\hline
\end{tabular}




\section{Declaration of interest}

The authors declare that there is no conflict of interest that could be perceived as prejudicing the impartiality of the research reported.

\section{Funding}

This research did not receive any specific grant from any funding agency in the public, commercial or not-for-profit sector.

\section{Acknowledgements}

The authors thank the physicians for referring their patients.

\section{References}

1 Eng C. RET proto-oncogene in the development of human cancer. Journal of Clinical Oncology 199917 380-393.

2 Kwok JB, Gardner E, Warner JP, Ponder BA \& Mulligan LM. Structural analysis of the human RET proto-oncogene using exon trapping. Oncogene 19938 2575-2582.

3 Ponder BA. The phenotypes associated with ret mutations in the multiple endocrine neoplasia type 2 syndrome. Cancer Research 199959 (7 Suppl) 1736s-1742s.

4 Eng C, Clayton D, Schuffenecker I, Lenoir G, Cote G, Gagel R, Ploos van Amstel HK, Lips CJ, Nishisho I, Takai SI et al. The relationship between specific RET proto-oncogene mutations and disease phenotype in multiple endocrine neoplasia type 2. International RET Mutation Consortium Analysis. Journal of the American Medical Association 1996 279 1575-1578. (doi:10.1001/jama.1996.03540190047028)

5 Mulligan LM \& Ponder BA. Genetic basis of endocrine disease: multiple endocrine neoplasia type 2. Journal of Clinical Endocrinology and Metabolism 199580 1989-1995.

6 Niccoli-Sire P, Murat A, Rohmer V, Franc S, Chabrier G, Baldet L, Maes B, Savagner F, Giraud S, Bezieau S et al. Familial medullary thyroid carcinoma with noncysteine RET mutations: phenotype-genotype relationship in a large series of patients. Journal of Clinical Endocrinology and Metabolism 200186 3746-3753. (doi:10.1210/jcem.86.8.7767)

7 Sarika HL, Papathoma A, Garofalaki M, Vasileiou V, Vlassopoulou B, Anastasiou E \& Alevizaki M. High prevalence of exon 8 G533C mutation in apparently sporadic medullary thyroid carcinoma in Greece. Clinical Endocrinology 20127 857-862. (doi:10.1111/j. 1365-2265.2012.04462.x)

8 Machens A, Lorenz K, Sekulla C, Höppner W, Frank-Raue K, Raue F \& Dralle H. Molecular epidemiology of multiple endocrine neoplasia 2: implications for RET screening in the new millennium. European Journal of Endocrinology 2013168 307-314. (doi:10.1530/EJE-12-0919)

9 Romei C, Mariotti S, Fugazzola L, Taccaliti A, Pacini F, Opocher G, Mian C, Castellano M, degli Uberti E, Ceccherini I et al. Multiple endocrine neoplasia type 2 syndromes (MEN 2): results from the ItaMEN network analysis on the prevalence of different genotypes and phenotypes. European Journal of Endocrinology 2010163 301-308. (doi:10.1530/EJE-10-0333)

10 American Thyroid Association Guidelines Task Force, Kloos RT, Eng C, Evans DB, Francis GL, Gagel RF, Gharib H, Moley JF, Pacini F, Ringel MD et al. Medullary thyroid cancer: management guidelines of the American Thyroid Association. Thyroid 200919 565-612. (doi:10.1089/thy.2008.0403)

11 Elisei R, Alevizaki M, Conte-Devolx B, Frank-Raue K, Leite V \& Williams GR. European Thyroid Association Guidelines for genetic testing and its clinical consequences in medullary thyroid cancer. European Thyroid Journal 20121 216-231. (doi:10.1159/000346174)
12 Da Silva AM, Maciel RM, Da Silva MR, Toledo SR, De Carvalho MB \& Cerutti JM. A novel germ-line point mutation in RET exon 8 (Gly533Cys) in a large kindred with familial medullary thyroid carcinoma. Journal of Clinical Endocrinology and Metabolism $2003 \mathbf{8 8}$ 5438-5443. (doi:10.1210/jc.2003-030997)

13 Castro MR, Thomas BC, Richards ML, Zhang J \& Morris JC. Multiple endocrine neoplasia type 2A due to an exon 8 (G533C) mutation in a large North American kindred. Thyroid 201323 1547-1552. (doi:10.1089/thy.2012.0599)

14 Casey R, Prendeville S, Joyce C \& O'Halloran D. First reported case in Ireland of MEN2A due to a rare mutation in exon 8 of the RET oncogene. Endocrinology, Diabetes \& Metabolism Case Reports 2013. Article ID:13-1144. (doi:10.1530/EDM-13-0044)

15 Pinna G, Orgiana G, Riola A, Ghiani M, Lai ML, Carcassi C \& Mariotti S. RET proto-oncogene in Sardinia: V804M is the most frequent mutation and may be associated with FMTC/MEN-2A phenotype. Thyroid 2007 17 101-104. (doi:10.1089/thy.2006.0198)

16 Qari F. RET codon 618 mutations in Saudi families with multiple endocrine neoplasia Type $2 \mathrm{~A}$ and familial medullary thyroid carcinoma. Annals of Saudi Medicine 201333 155-158. (doi:10.5144/02564947.2013.155)

17 Chang CF, Yang WY, Su YN, Wu IL \& Chang TC. Mutational spectrum of multiple endocrine neoplasia type 2 and sporadic medullary thyroid carcinoma in Taiwan. Journal of the Formosan Medical Association 2009 108 402-408. (doi:10.1016/S0929-6646(09)60084-X)

18 Chung YJ, Kim HH, Kim HJ, Min YK, Lee MS, Lee MK, Kim KW, Ki CS, Kim JW \& Chung JH. RET proto-oncogene mutations are restricted to codon 634 and 618 in Korean families with multiple endocrine neoplasia 2A. Thyroid 200414 813-818. (doi:10.1089/105072 5042451220)

19 Prazeres HJ, Rodrigues F, Figueiredo P, Naidenov P, Soares P, Bugalho MJ, Lacerda M, Campos B \& Martins TC. Occurrence of the Cys611Tyr mutation and a novel Arg886Trp substitution in the RET proto-oncogene in multiple endocrine neoplasia type 2 families and sporadic medullary thyroid carcinoma cases originating from the central region of Portugal. Clinical Endocrinology 200664 659-666. (doi:10.1111/j.1365-2265.2006.02524.x)

20 Jindrichová S, Vcelák J, Vlcek P, Neradilová M, Nemec J \& Bendlová B. Screening of six risk exons of the RET proto-oncogene in families with medullary thyroid carcinoma in the Czech Republic. Journal of Endocrinology 2004183 257-265. (doi:10.1677/joe.1.05838)

21 Sharma BP \& Saranath D. RET gene mutations and polymorphisms in medullary thyroid carcinomas in Indian patients. Journal of Biosciences 201136 603-611. (doi:10.1007/s12038-011-9095-0)

22 Fernandez RM, Navarro E, Antinolo G, Ruiz-Ferrer M \& Borrego S. Evaluation of the role of RET polymorphisms/haplotypes as modifier loci for MEN 2, and analysis of the correlation with the type of RET mutation in a series of Spanish patients. International Journal of Molecular Medicine 200617 575-581. (doi:10.3892/ijmm.17.4.575)

23 Erdogan M, Gursoy A, Gullu S, Aydintug S, Kucuk B, Baskal N, Kamel N, Hoppner W \& Erdogan G. Clinical and genetic experience in Turkish multiple endocrine neoplasia type 2 families. Endocrinologist $2007 \mathbf{1 7}$ 273-277. (doi:10.1097/TEN.0b013e31815151b5)

24 Fazioli F, Piccinini G, Appolloni G, Bacchiocchi R, Palmonella G, Recchioni R, Pierpaoli E, Silvetti F, Scarpelli M, Bruglia M et al. A new germline point mutation in Ret exon 8 (cys515ser) in a family with medullary thyroid carcinoma. Thyroid 200818 775-782. (doi:10.1089/ thy.2007.0365)

25 Alvandi E, Akrami SM, Chiani M, Hedayati M, Nayer BN, Tehrani MR, Nakhjavani M \& Pedram M. Molecular analysis of the RET protooncogene key exons in patients with medullary thyroid carcinoma: a comprehensive study of the Iranian population. Thyroid 201121 373-383. (doi:10.1089/thy.2010.0267)

26 Scheuba C, Kaserer K, Moritz A, Drosten R, Vierhapper H, Bieglmayer C, Haas OA \& Niederle B. Sporadic hypercalcitoninemia: clinical and 
therapeutic consequences. Endocrine-Related Cancer 200916 243-253. (doi:10.1677/ERC-08-0059)

27 Raue F \& Frank-Raue K. Genotype-phenotype correlation in multiple endocrine neoplasia type 2. Clinics 201267 (S1) 69-75. (doi:10.6061/ clinics/2012(Sup01)13)

28 Moers AM, Landsvater RM, Schaap C, Jansen-Schillhorn van Veen JM, de Valk IA, Blijham GH, Höppener JW, Vroom TM, van Amstel HK \&
Lips CJ. Familial medullary thyroid carcinoma: not a distinct entity? Genotype-phenotype correlation in a large family American Journal of Medicine 1996101 635-641. (doi:10.1016/S0002-9343(96)00330-0)

29 Fugazzola L, De Leo S \& Perrino M. The optimal range of RET mutations to be tested: European comments to the guidelines of the American Thyroid Association. Thyroid Research 20136 (Suppl 1) S8. (doi:10.1186/ 1756-6614-6-S1-S8)

Received 28 September 2014

Revised version received 4 December 2014

Accepted 26 January 2015 